\title{
New-onset atrial fibrillation during COVID-19 infection predicts poor prognosis
}

\author{
Ana Pardo Sanz, Luisa Salido Tahoces, Rodrigo Ortega Pérez, Eduardo González Ferrer, \\ Ángel Sánchez Recalde, José Luis Zamorano Gómez
}

University Hospital Ramón y Cajal, Madrid, Spain

\begin{abstract}
Background: Severe acute respiratory syndrome coronavirus 2 (SARS-CoV-2) pandemic has led to a paradigm shift in healthcare worldwide. Little is known about the impact on the cardiovascular system, and the incidence and consequences of new onset of atrial fibrillation $(A F)$ in infected patients remain unclear. The aim of this study was to analyze the cardiovascular outcomes of patients with newonset $A F$ and coronavirus disease 2019 (COVID-19) infection.

Methods: This observational study analyzed a sample of 160 consecutive patients hospitalized due to COVID-19. A group with new-onset $A F(n=12)$ was compared with a control group (total: $n=148$, sinus rhythm: $n=118$, previous $A F: n=30$ ). New-onset $A F$ patients were significantly older and hypertensive, as well as presenting more frequently with a history of acute coronary syndrome and renal dysfunction. This group showed a higher incidence of thromboembolic events $(41.7 \%$ vs. $4.1 \%$; $p<0.001)$, bleeding (33.3\% vs. 4.7\%, $p=0.005)$, a combined endpoint of thrombosis and death (58.3\% vs. $19.6 \%, p=0.006)$ and longer hospital stays (16.4 vs. 8.6 days, $p<0.001$ ), with no differences in all-cause mortality.

Results: In multivariate analysis, adjusted by potential confounding factors, new-onset AF demonstrated a 14.26 odds ratio for thromboembolism (95\% confidence interval $2.86-71.10, p<0.001$ ).

Conclusions: New-onset AF in COVID-19 patients presumably has a notable impact on prognosis. The appearance of new-onset $A F$ is related to worse cardiovascular outcomes, considering it as an independent predictor of embolic events. Further studies are needed to identify patients with COVID-19 at high risk of developing "de novo" $A F$, provide early anticoagulation and minimize the embolic risk of both entities. (Cardiol J 2021; 28, 1: 34-40)
\end{abstract}

Key words: new-onset atrial fibrillation, COVID-19 prognostic, SARS-CoV-2, embolism

\section{Introduction}

Coronavirus disease 2019 (COVID-19), a viral respiratory illness caused by severe acute respiratory syndrome coronavirus 2 (SARS-CoV-2), has caused a pandemic which is overwhelming health care systems worldwide. Affected patients have been reported to have an inflammatory state that may predispose patients to in-hospital cardiovascular complications, such as myocardial damage, atrial fibrillation (AF), and stroke. Furthermore, patients with pre-existing health conditions such as obesity, pulmonary disease, hypertension and heart failure are at higher risk for a more severe infection by SARS-CoV-2. The disease can trigger exacerbated inflammatory responses that can be challenging for patients with heart conditions.

There is a lack of information about the incidence and the consequences of arrhythmias related to the virus. As with any infection, there can be an increase of stress on the body from which arrhythmias can arise [1]. AF is the most common pathologic of arrhythmia, and its incidence is increased in the presence of an infection [2].

The presence of palpitations has been reported as one of the most common initial symptom of the

Address for correspondence: Ana Pardo Sanz, MD, PhD, University Hospital Ramón y Cajal, Madrid, Spain, tel: 0034665420502, e-mail: anapardosanz0@gmail.com

Received: 23.06.2020 Accepted: 2.09.2020

This article is available in open access under Creative Common Attribution-Non-Commercial-No Derivatives 4.0 International (CC BY-NC-ND 4.0) license, allowing to download articles and share them with others as long as they credit the authors and the publisher, but without permission to change them in any way or use them commercially. 
disease (7.3\%) [3]. In 138 patients from Wuhan who were hospitalized with COVID-19-related infection, arrhythmias were reported in $17 \%$ of the general cohort and in $44 \%$ of the patients admitted to an intensive care unit [4]. The most common arrhythmia overall in patients with COVID-19 is sinus tachycardia, but the most frequent pathologic arrhythmias include AF, atrial flutter and monomorphic or polymorphic ventricular tachycardia. The prevalence of AF in COVID-19 patients is substantial when combining both pre-existing and newonset AF. The onset of AF may be related to electrolyte abnormalities, dehydration and hypoxia [5]. Several previous studies have demonstrated that new onset atrial arrhythmias are associated with increased morbidity and mortality $[6,7]$. The outcomes in patients with new-onset AF, pre-existing $\mathrm{AF}$, and sinus rhythm remain unclear in patients with COVID-19.

Atrial fibrillation is a common cause of stroke, hospitalization and death, whereas anticoagulation therapy for the prevention of stroke can trigger bleeding events. The management of AF regarding the use of antithrombotic therapies in the setting of COVID-19 disease, in clinical practice, does not differ from the routine management [8]. On the other hand, coagulopathy is a common abnormality in patients with COVID-19 disease and these patients seem to have a higher risk of developing thromboembolic events [9]. The balance between embolic and bleeding risk in these patients is challenging.

The current study aims to evaluate the impact of new-onset $\mathrm{AF}$ compared with pre-existing $\mathrm{AF}$ and sinus rhythm on long-term mortality, stroke, and bleeding in COVID patients.

\section{Methods}

The present observational single-center review consists of consecutive patients hospitalized with COVID-19-related infection in a tertiary hospital and prospective follow-up until discharge. A total of 160 consecutive patients were enrolled.

Patients hospitalized with COVID-19 infection between March and April 2020 were studied. Inclusion criteria were age $>18$ years old and diagnosis of COVID-19 confirmed by polymerase chain reaction. For comparison purposes, two groups were established: the new-onset $\mathrm{AF}$ group, which constituted consecutive patients with "de novo" AF during the hospitalization; and the control group, formed by patients in sinus rhythm or with previous AF hospitalized with COVID-19 during the same period. In the present study, the groups were defined as new-onset $\mathrm{AF}$ and control group (with pre-existing $\mathrm{AF}$ or sinus rhythm), to scrutinize the role of new-onset AF.

No explicit exclusion criteria were defined other than valvular AF or mechanic cardiac prostheses to avoid selection bias.

All data were captured using a dedicated electronic case report form. Clinical and therapeutic data were collected. The risk of thromboembolic and bleeding events was assessed by calculating the $\mathrm{CHA}_{2} \mathrm{DS}_{2}$-VASc and the HAS-BLED scores in all patients, because the international normalized ratio (INR) is not pertinent for the use of heparin (and no patient was in treatment with warfarin), the "labile INR" component from the original HAS-BLED score was not included. Therefore, the maximum points for this cohort for the HAS-BLED score was 8 instead of 9 .

The prevalence of new-onset AF was documented by electrocardiograms, rhythm strips, and Holter monitors. Patients were examined and pulse tests were performed daily.

Clinical follow-up was performed during the hospitalization, with special attention to anticoagulation therapy, and the incidence of embolic and bleeding events was monitored.

The primary endpoint was thrombosis, defined as a combination of ischemic stroke, systemic embolism and pulmonary embolism. Ischemic stroke was considered in the case of an abrupt onset of a focal neurological deficit non-attributable to an identifiable nonvascular cause and excluded intracranial bleeding. Systemic embolic event consisted on an abrupt episode of arterial occlusion with clinical or radiologic documentation in the absence of prior instrumentation.

The primary safety outcome for the current study included fatal bleeding, bleeding into a critical organ (intracranial, intraspinal, pericardial, retroperitoneal or intramuscular with compartment syndrome) or relevant bleeding with a hemoglobin drop of $\geq 2 \mathrm{~g} / \mathrm{dL}$. The definition of major bleeding events was consistent with the International Society of Thrombosis and Hemostasis (ISTH) criteria [10].

The study protocol complied with the Declaration of Helsinki and it was authorized by the Reference Ethic Committee and the Local Ethic Committees of the hospital. Access to the medical records was granted for retrospective analysis.

There has been no patient and public involvement in this work. 
Table 1. Baseline demographics and patient characteristics.

\begin{tabular}{lccc}
\hline & $\begin{array}{c}\text { New onset AF } \\
(\mathbf{n}=12)\end{array}$ & $\begin{array}{c}\text { Control group } \\
\text { (n = 148) }\end{array}$ & $\begin{array}{c}\text { P-value } \\
\text { (univariate) }\end{array}$ \\
\hline Sex (female) & $\mathrm{N}=4(33.3 \%)$ & $\mathrm{N}=60(40.5 \%)$ & 0.43 \\
Age (years), mean $\pm \mathrm{SD}$ & $75.9 \pm 9.6$ & $64.9 \pm 16.3$ & 0.007 \\
Arterial hypertension & $9(75 \%)$ & $66(44.6 \%)$ & 0.04 \\
Diabetes mellitus & $3(25 \%)$ & $22(14.9 \%)$ & 0.28 \\
Previous myocardial infarction & $4(33.3 \%)$ & $10(6.8 \%)$ & 0.01 \\
Congestive heart failure & $2(16.7 \%)$ & $11(7.5 \%)$ & 0.25 \\
Previous stroke/systemic embolism & $0(0 \%)$ & $12(8.1 \%)$ & 0.38 \\
Previous bleeding & $1(8.3 \%)$ & $9(6.1 \%)$ & 0.40 \\
Abnormal liver function & $6(50 \%)$ & $43(29.1 \%)$ & 0.12 \\
Renal dysfunction & $5(41.7 \%)$ & $22(14.9 \%)$ & 0.03 \\
CHA ${ }_{2}$ DS ${ }_{2}$ VASc & $1.66 \pm 1.51$ & $2.1 \pm 1.7$ & 0.39 \\
HAS-BLED & $1.19 \pm 1.12$ & $1.5 \pm 1.3$ & 0.17 \\
Anticoagulation therapy & $3(25 \%)$ & $33(22.3 \%)$ & 0.53 \\
Troponin I [ng/mL] & $0.4 \pm 1.0$ & $0.5 \pm 26.5$ & 0.87 \\
D-dimer [ng/mL] & $10833 \pm 18959$ & $3642 \pm 9936$ & 0.03 \\
Hemoglobin $[\mathrm{g} / \mathrm{dL}]$ & $13.0 \pm 0.9$ & $14.2 \pm 7.2$ & 0.50 \\
\hline
\end{tabular}

Values are expressed as number (\%) unless otherwise indicated; SD - standard deviation; $\mathrm{AF}$ - atrial fibrillation; $\mathrm{CHA}_{2} \mathrm{DS}_{2}-\mathrm{VASc}-\mathrm{Conges}$ tive heart failure, Hypertension, Age > 75 years, Diabetes mellitus, Stroke, Vascular disease, Age 65-74 years, Sex category; HAS-BLED Hypertension, Abnormal renal/liver function, Stroke, Bleeding history or predisposition, Labile international normalized ratio, Elderly, Drugs/alcohol

\section{Statistics analysis}

Variables are presented as number (percentage) or mean \pm standard deviation (SD), as appropriate. Baseline characteristics between the "de novo" AF and control groups, were compared with the $\chi^{2}$ test for discrete variables and the Student $\mathrm{t}$-test for continuous variables provided that populations were normally distributed. Multivariable logistic analysis was used to determine independent predictors of embolic events, including variables with statistical significance on univariate analysis and potential confounding factors. Observations with missing data were excluded from the analysis ( $<1 \%$ from total). Analysis was conducted using SPSS software V.22.0, with a two-tailed significance value of 0.05 .

\section{Results}

\section{Patient characteristics}

A total of 160 consecutive patients with COVID-19 infection were enrolled, $7.5 \%$ with new-onset $\mathrm{AF}(\mathrm{n}=12)$ and $92.5 \%$ in the control group $(n=148)$. In the control group, 30 patients had previous diagnostic of $\mathrm{AF}$ and the rest of the patients $(n=118)$ were in sinus rhythm.
New-onset AF patients were studied according to their baseline characteristics, in-hospital features and clinical outcomes. The main demographic and clinical characteristics of the study population are shown in Table 1.

New-onset AF was more frequent in older patients $(p=0.007)$, hypertensive $(p=0.04)$, history of previous acute coronary syndrome $(\mathrm{p}=0.01)$ and renal dysfunction $(\mathrm{p}=0.03)$. No differences were seen regarding other cardiovascular risk factors or comorbidities. Baseline embolic risk, as assessed by $\mathrm{CHA}_{2} \mathrm{DS}_{2}-\mathrm{VASc}$, and baseline bleeding risk (HAS-BLED) did not show significant differences between groups. The chosen anticoagulation therapy was low molecular weight heparin in a therapeutic dose $(1 \mathrm{mg} / \mathrm{kg} / 12 \mathrm{~h})$, with no differences between groups (new-onset $\mathrm{AF}$ and control group). For the rest of the patients hospitalized due to COVID-19 infection, low molecular weight heparin in a prophylactic dosage (40 $\mathrm{mg}$ once daily and $20 \mathrm{mg}$ for patients with severe renal impairment) was prescribed. Regarding laboratory parameters, higher values of peak $\mathrm{D}$-dimer were recorded in the group with "de novo" AF ( $\mathrm{p}=0.03)$. Only 7 patients had been admitted to the intensive care unit in the total sample, $16 \%(\mathrm{n}=2)$ in the group 
Table 2. Events during hospitalization in patients with COVID-19.

\begin{tabular}{lccc}
\hline Events & $\begin{array}{c}\text { New-onset atrial } \\
\text { fibrillation }(\mathbf{n}=\mathbf{1 2})\end{array}$ & $\begin{array}{c}\text { Control group } \\
(\mathbf{n}=148)\end{array}$ & $\begin{array}{c}\text { P-value } \\
\text { (univariate) }\end{array}$ \\
\hline Embolic events & $5(41.7 \%)$ & $6(4.1 \%)$ & $<0.001$ \\
Bleeding events & $4(33.3 \%)$ & $7(4.7 \%)$ & 0.005 \\
All-cause mortality & $4(33.3 \%)$ & $26(17.6 \%)$ & 0.16 \\
Death + embolic event & $7(58.3 \%)$ & $29(19.6 \%)$ & 0.006 \\
Days of admission & $16.4 \pm 13.0$ & $8.6 \pm 6.5$ & $<0.001$ \\
\hline
\end{tabular}

of new-onset $\mathrm{AF}$ and $3.3 \%(\mathrm{n}=5)$ in the control group, $\mathrm{p}=0.08$ (the Fisher exact test).

Both groups received treatment for COVID-19 according to the hospital protocol at that moment, that included hydroxychloroquine and azithromycin if there were no contraindications, antiviral, dexamethasone if needed and oxygen support, with no differences between groups.

\section{Incidence of major outcomes}

New-onset AF was a predictor of embolic events $(\mathrm{p}<0.001)$ during hospital stay. The incidence of bleeding events during hospitalization was also higher in the group with "de novo" AF $(p=0.005)$. When both embolic events and all-cause mortality were assessed collectively, new-onset $\mathrm{AF}$ was related to worse prognosis $(\mathrm{p}=0.006)$. The embolic events in the group with new-onset AF were one stroke, two systemic embolism and one pulmonary embolism, and none of these patients were receiving anticoagulation therapy. Patients with COVID-19 disease and new-onset $\mathrm{AF}$ had a higher incidence of bleeding events, and gastrointestinal bleeding was the main source of hemorrhages in both groups. All-cause mortality during the admission showed no differences between the groups. The hospital stay was longer in the group with new-onset AF $(\mathrm{p}<0.001)$. The events in the population are shown in Table 2.

In multivariate analysis, only the new onset of $\mathrm{AF}$ remained an independent predictor of embolic events, carrying a risk 14.26 times higher than in the control group (95\% confidence interval $2.86-71.10, \mathrm{p}<0.001)$. The multivariate analysis is shown in Table 3. The characteristics of the group with new-onset AF are shown in Table 4.

\section{Discussion}

The present study shows that:

- New-onset of AF during hospital stay in pa-
Table 3. Independent predictors of embolic events in patients with COVID-19 infection.

\begin{tabular}{lccc}
\hline $\begin{array}{l}\text { Multivariate } \\
\text { analysis }\end{array}$ & $\begin{array}{l}\text { Odds } \\
\text { ratio }\end{array}$ & $95 \% \mathrm{Cl}$ & P-value \\
\hline New onset AF & 14.26 & $2.86-71.10$ & $<0.001$ \\
Age & 1.00 & $0.95-1.06$ & 0.65 \\
Arterial hypertension & 2.04 & $0.40-10.29$ & 0.26 \\
Renal dysfunction & 0.38 & $0.04-3.03$ & 0.41 \\
Bleeding events & 1.82 & $0.21-15.66$ & 0.96 \\
\hline
\end{tabular}

$\mathrm{AF}-$ atrial fibrillation; $\mathrm{Cl}$ - confidence interval

tients with COVID-19 is an independent predictor of in-hospital embolic events;

- New-onset AF is associated with worse clinical features during hospitalization in terms of more bleeding events, and more events in the combined end-point (death + embolic events);

- New-onset AF is associated with a longer hospital stay.

Atrial fibrillation is a common cause of stroke and embolism, especially when it is not treated with anticoagulation therapy when indicated, as prevention of stroke. On the other hand, COVID-19 may predispose patients to thrombotic disease, both in the venous and arterial circulations, due to excessive inflammation, platelet activation, endothelial dysfunction, and stasis [11]. Preliminary reports suggest that hemostatic abnormalities, including disseminated intravascular coagulation, occurs in patients affected by COVID-19 [12]. This makes management challenging because of anticoagulation therapy in patients with both conditions.

It remains unclear whether hemostatic changes are a specific effect of SARS-CoV-2 or are a consequence of cytokine storm that precipitates the onset of systemic inflammatory response syndrome, as observed in other viral diseases [13].

It is already known that thrombogenic phenomenon in $\mathrm{AF}$ is not only limited to local factors 
Table 4. Characteristics of patients with COVID-19 infection and new-onset atrial fibrillation.

\begin{tabular}{|c|c|c|c|c|c|c|}
\hline Patient & $\begin{array}{c}\text { Age } \\
\text { (years-old) }\end{array}$ & $\begin{array}{c}\text { Days of } \\
\text { admission }\end{array}$ & $\begin{array}{c}\mathrm{CHA}_{2} \mathrm{DS}_{2-} \\
\text {-VASc }\end{array}$ & Anticoagulation therapy & $\begin{array}{l}\text { Embolic } \\
\text { events }\end{array}$ & $\begin{array}{l}\text { Bleeding } \\
\text { events }\end{array}$ \\
\hline 1 & 74 & 4 & 1 & $\begin{array}{l}\text { Low molecular weight heparin } \\
\qquad(1 \mathrm{mg} / \mathrm{kg} / 24 \mathrm{~h})\end{array}$ & No events & No events \\
\hline 2 & 82 & 6 & 2 & Prophylactic heparin & No events & No events \\
\hline 3 & 57 & 15 & 0 & Prophylactic heparin & No events & No events \\
\hline 4 & 88 & 7 & 3 & $\begin{array}{l}\text { Low molecular weight heparin } \\
\qquad(1 \mathrm{mg} / \mathrm{kg} / 24 \mathrm{~h})\end{array}$ & No events & No events \\
\hline 5 & 82 & 14 & 2 & Prophylactic heparin & No events & No events \\
\hline 6 & 82 & 38 & 2 & Prophylactic heparin & $\begin{array}{l}\text { Systemic } \\
\text { embolism }\end{array}$ & No events \\
\hline 7 & 82 & 12 & 2 & Prophylactic heparin & $\begin{array}{l}\text { Systemic } \\
\text { embolism }\end{array}$ & No events \\
\hline 8 & 58 & 8 & 1 & Prophylactic heparin & No events & $\begin{array}{c}\text { Gastrointestina } \\
\text { bleeding }\end{array}$ \\
\hline 9 & 73 & 17 & 1 & Prophylactic heparin & $\begin{array}{l}\text { Pulmonary } \\
\text { embolism }\end{array}$ & Epistaxis \\
\hline 10 & 75 & 28 & 2 & Prophylactic heparin & Stroke & $\begin{array}{c}\text { Gastrointestina } \\
\text { bleeding }\end{array}$ \\
\hline 11 & 76 & 40 & 2 & Prophylactic heparin & Stroke & $\begin{array}{c}\text { Gastrointestina } \\
\text { bleeding }\end{array}$ \\
\hline 12 & 82 & 8 & 2 & $\begin{array}{l}\text { Low molecular weight heparin } \\
\qquad(1 \mathrm{mg} / \mathrm{kg} / 24 \mathrm{~h})\end{array}$ & No events & No events \\
\hline
\end{tabular}

such as stasis or a dysfunctional atrium contraction. A generalized hypercoagulable state has been proposed, too. This may lead to concern that other proinflammatory and procoagulant situations, such as cancer or infections could have a synergic effect on cardiovascular events [14].

New-onset AF was associated with a higher incidence of embolic events, and this was regardless of the use of anticoagulation (there are no significant differences between the groups). However, the rate of bleeding events was also higher, and this points out that the onset of AF probably indicates a more inflammatory scenario, with more severe hypoxia and a more important coagulopathy in patients with "de novo" $\mathrm{AF}$.

The use of anticoagulation with a therapeutic dosage is not recommended in general for all patients with COVID-19, if they do not have AF or other indications. In the present study, bleeding events were more frequent in patients with anticoagulation, with no differences between the groups (new-onset AF and control group). However, the incidence of embolism was higher in patients with new-onset AF (41.7\%). All patients with embolic events in our sample were not receiving anticoagulation therapy (with a therapeutic dosage). If we look at the control group, patients with AF were correctly treated with anticoagulation therapy, and no embolic events were observed. All the events in this group corresponded to patients with sinus rhythm and without anticoagulation therapy $(4.1 \%)$. The majority of patients with new-onset $\mathrm{AF}$ were not receiving anticoagulation therapy (75\%, 9 patients). This can be explained because the diagnosis of AF was after the embolic event (in 5 patients), and because of high bleeding risk (in 4 patients).

Thus, it would be of interest to identify predictors for the onset of AF, in order to manage the challenging balance between embolic and bleeding risk. A variety of further factors, including congestive heart failure, ischemic heart disease and hypertension have been addressed as potential co-factors for the development of new-onset AF in critically ill patients [15]. In the current study, similar factors like age, arterial hypertension, history of myocardial infarction, renal dysfunction and a higher value of $\mathrm{D}$-dimer, acted as possible co-factors for the new onset of AF in patients with COVID-19. The present data support the hypothesis that these factors might play a major role in the development of AF in COVID-19 patients.

New onset of AF is common in several diseases and, on the other hand, it has been associated 
with an increased incidence of other complications including stroke, increased hospital length of stay and increased cost of hospitalization. Prevention of AF has been a reasonable clinical goal, consequently, many randomized trials have evaluated the effectiveness of pharmacological and non-pharmacological interventions in other pathologies, such as cardiac surgery [16-20].

It has been shown that agents with anti-inflammatory and antioxidant properties decreased postoperative AF rates in previous studies. Further studies are needed in order to identify predictors and potential treatments that might be useful for patients with "de novo" AF in the context of COVID disease. The pathophysiological mechanism underlying the development of $\mathrm{AF}$ and the incidence of embolic events in COVID-19 patients is not known. However, the systemic inflammatory response per se, could be a trigger for both conditions in COVID-19 patients.

Is the development of the arrhythmia just a marker of the severity of the infection? Does the onset of AF imply per se, a higher incidence of embolic and bleeding events? Little is known about triggers that could modify the coagulation cascade in patients with COVID-19, but hemostatic changes are common during the infection.

\section{Limitations of the study}

The number of patients studied with new-onset $\mathrm{AF}$ was small, which could limit the number of independent predictors identified and the consistency of the results. However, the statistical difference is such that it allows drawing preliminary conclusions.

\section{Conclusions}

Patients with new-onset AF in the context of COVID-19 disease have worse prognosis in terms of higher incidence of embolic events. The onset of AF has implications in patients with COVID-19 that go beyond the simple presence of the arrhythmia, and the outcomes in these patients is worse than in patients with previous $\mathrm{AF}$ (and, of course, than patients in sinus rhythm). Patients with "de novo" $\mathrm{AF}$ also have a higher incidence of bleeding events, and a longer hospital stay. Further investigations are needed to enable strategies that may predict the new onset of $\mathrm{AF}$, in order to identify high risk patients, provide an early treatment and thus minimize the embolic risk of COVID-19 and AF.

Conflict of interest: None declared

\section{References}

1. Meierhenrich R, Steinhilber E, Eggermann C, et al. Incidence and prognostic impact of new-onset atrial fibrillation in patients with septic shock: a prospective observational study. Crit Care. 2010; 14(3): R108, doi: 10.1186/cc9057, indexed in Pubmed: 20537138.

2. Zulkifly H, Lip GYH, Lane DA. Epidemiology of atrial fibrillation. Int J Clin Pract. 2018; 72(3): e13070, doi: 10.1111/ijcp.13070, indexed in Pubmed: 29493854.

3. Driggin E, Madhavan MV, Bikdeli B, et al. Cardiovascular considerations for patients, health care workers, and health systems during the COVID-19 pandemic. J Am Coll Cardiol. 2020; 75(18): 2352-2371, doi: 10.1016/j.jacc.2020.03.031, indexed in Pubmed: 32201335 .

4. Wang D, Hu Bo, Hu C, et al. Clinical characteristics of 138 hospitalized patients with 2019 novel coronavirus-infected pneumonia in Wuhan, China. JAMA. 2020; 323(11): 1061-1069, doi: 10.1001/ jama.2020.1585, indexed in Pubmed: 32031570.

5. Lakkireddy DR, Chung MK, Gopinathannair R, et al. Guidance for Cardiac Electrophysiology During the Coronavirus (COVID-19) Pandemic from the Heart Rhythm Society COVID-19 Task Force. Hear Rhythm. 2020.

6. Galvão Braga C, Ramos V, Vieira C, et al. New-onset atrial fibrillation during acute coronary syndromes: predictors and prognosis. Rev Port Cardiol. 2014; 33(5): 281-287, doi: 10.1016/j. repc.2013.10.017, indexed in Pubmed: 24931182.

7. Mentias A, Saad M, Girotra S, et al. Impact of pre-existing and newonset atrial fibrillation on outcomes after transcatheter aortic valve replacement. JACC Cardiovasc Interv. 2019; 12(21): 2119-2129, doi: 10.1016/j.jcin.2019.06.019, indexed in Pubmed: 31629743.

8. Kirchhof P, Benussi S, Kotecha D, et al. ESC Scientific Document Group. 2016 ESC Guidelines for the management of atrial fibrillation developed in collaboration with EACTS. Eur Heart J. 2016; 37(38): 2893-2962, doi: 10.1093/eurheartj/ehw210, indexed in Pubmed: 27567408.

9. Llitjos JF, Leclerc M, Chochois C, et al. High incidence of venous thromboembolic events in anticoagulated severe COVID-19 patients. J Thromb Haemost. 2020; 18(7): 1743-1746, doi: 10.1111/ jth.14869, indexed in Pubmed: 32320517.

10. Schulman S, Kearon C. Definition of major bleeding in clinical investigations of antihemostatic medicinal products in non-surgical patients. J Thromb Haemost. 2005; 3(4): 692-694, doi: 10.1111/j.1538-7836.2005.01204.x, indexed in Pubmed: 15842354 .

11. Bikdeli B, Madhavan MV, Jimenez D, et al. COVID-19 and thrombotic or thromboembolic disease: implications for prevention, antithrombotic therapy, and follow-up: JACC state-of-the-art review. J Am Coll Cardiol. 2020; 75(23): 2950-2973, doi: 10.1016/j. jacc.2020.04.031, indexed in Pubmed: 32311448.

12. Fan BE, Chong VC, Chan SS, et al. Hematologic parameters in patients with COVID-19 infection. Am J Hematol. 2020; 95(6): E131-E134, doi: 10.1002/ajh.25774, indexed in Pubmed: 32129508.

13. Mehta P, McAuley DF, Brown M, et al. COVID-19: consider cytokine storm syndromes and immunosuppression. Lancet. 2020; 395(10229): 1033-1034, doi: 10.1016/S0140-6736(20)30628-0, indexed in Pubmed: 32192578.

14. Chu G, Versteeg HH, Verschoor AJ, et al. Atrial fibrillation and cancer - an unexplored field in cardiovascular oncology. Blood 
Rev. 2019; 35: 59-67, doi: 10.1016/j.blre.2019.03.005, indexed in Pubmed: 30928168.

15. Seguin $P$, Signouret T, Laviolle B, et al. Incidence and risk factors of atrial fibrillation in a surgical intensive care unit. Crit Care Med. 2004; 32(3): 722-726, doi: 10.1097/01.ccm.0000114579.56430.e0, indexed in Pubmed: 15090953.

16. Ozaydin M, Peker O, Erdogan D, et al. Oxidative status, inflammation, and postoperative atrial fibrillation with metoprolol vs carvedilol or carvedilol plus $\mathrm{N}$-acetyl cysteine treatment. Clin Cardiol. 2014; 37(5): 300-306, doi: 10.1002/clc.22249, indexed in Pubmed: 24477817.

17. DiNicolantonio JJ, Beavers CJ, Menezes AR, et al. Meta-analysis comparing carvedilol versus metoprolol for the prevention of postoperative atrial fibrillation following coronary artery bypass grafting. Am J Cardiol. 2014; 113(3): 565-569, doi: 10.1016/j. amjcard.2013.10.020, indexed in Pubmed: 24332247.

18. Cook RC, Yamashita MH, Kearns M, et al. Prophylactic magnesium does not prevent atrial fibrillation after cardiac surgery: a meta-analysis. Ann Thorac Surg. 2013; 95(2): 533-541, doi: 10.1016/j.athoracsur.2012.09.008, indexed in Pubmed: 23141526.

19. Viviano A, Kanagasabay R, Zakkar M. Is perioperative corticosteroid administration associated with a reduced incidence of postoperative atrial fibrillation in adult cardiac surgery? Interact Cardiovasc Thorac Surg. 2014; 18(2): 225-229, doi: 10.1093/ icvts/ivt486, indexed in Pubmed: 24254538.

20. Worden JC, Asare K. Postoperative atrial fibrillation: role of inflammatory biomarkers and use of colchicine for its prevention. Pharmacotherapy. 2014; 34(11): 1167-1173, doi: 10.1002/ phar.1485, indexed in Pubmed: 25283810. 